\title{
Dynamic Performance Implications of the Power Conditioner Grid-Connected for Photovoltaic Source
}

\author{
C. Peraza ${ }^{1}$, F. González-Longatt ${ }^{2,3}$ and C. Villanueva ${ }^{4}$ \\ ${ }^{1}$ Departamento de Ingenieria Electrica \\ Instituto Universitario de Tecnología Valencia, 2122 Valencia (Venezuela) \\ phone:+58 0241-8687812, e-mail: cperazam@cantv.net \\ 2 Departamento de Ingeniería Eléctrica \\ Universidad Nacional Experimental Politécnica de la Fuerza Armada, 2122 Maracay (Venezuela) \\ phone: +58 414 4572832, fax:+58 243 5546921, email : fglongatt@ieee.org \\ ${ }^{3}$ PhD Student, Escuela de Ingeniería Eléctrica \\ Universidad Central de Venezuela, 1010 Caracas (Venezuela) \\ phone: +58 414 4572832, fax:+58 212 6053231, email: flongatt@elecrisc.ing.ucv.ve \\ 4 Facultad de Ingeniería, Escuela de Eléctrica \\ Universidad de Carabobo, 2022 Valencia (Venezuela) \\ phone: +58 0412-8893302, email: cvillanu@uc.edu.ve
}

\begin{abstract}
The abstract in placed in the left-hand column and starts at about $11 \mathrm{~cm}$ from de top of the page.

It should give concise information on the aims, the methods, the results and the conclusions of the paper. Its length should not exceed 200 words.
\end{abstract}

\section{Key words}

Please write the main key words of your text (3 to 6) separated by commas.

\section{Introduction}

Distributed resources (DR) include a variety of energy sources, such as turbines, photovoltaics (PV), fuel cells, and storage devices, with capacities in the $1 \mathrm{~kW}$ to 10MW range [1]. Renewable energy resources will be an increasingly important part of power generation in the new millennium. One of them, PV system placed in appropriate location at key locations within an existing electric distribution network, may be useful as grid support. This can increase the locally available power and enhancing the overall system reliability [2]. The PV system produce dc power, then requires an interface with the electrical grid. An inverter is responsible for the conversion from DC to the desired AC voltage magnitude and angle [2]. Although inverter topologies used for power application have traditionally been current sourced, in recent years, voltage source inverters (VSI) have been increasingly used for power application, like photovoltaic power systems, and battery storage systems [3]. Power electronics provide the control and flexibility required by the Distributed Energy Resources (DER) [6].
Control schemes for VSI's system environments has formed the topic of some works [4]. Power electronics plays a critical role in the DG dynamic behaviors [5]. This paper first presents the models of the PV system on grid support application: PV generator modeled with moderate complexity: including temperature dependence and effective control scheme for VSI is used to meet support to grid. Finally, the dynamic performance of the models is demonstrated with simulation results.

\section{PV System Description and Modeling}

A PV system operating for electrical grid support consists mainly in two components: PV generator, and inverter. A simplified electrical diagram of the PV system studied is depicted in Fig. 1.

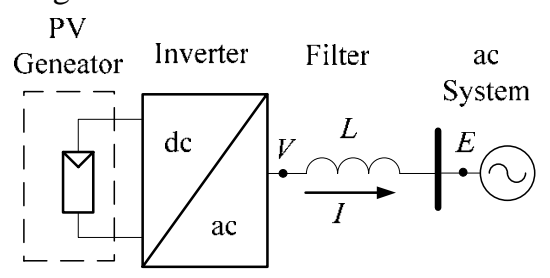

Fig. 1. Support to grid PV system

The goal of the system illustrated in Fig. 1 is supply electrical power to ac network with constant amplitude senoidal voltage from the PV during favorable weather condition. This system do not designed to base load supply, but to be useful the generation of opportunity, in conditions of favorable climate.

\section{A. PV Generator}

The PV generator is the whole assembly of solar cells, connections, protective parts, supports etc. In the present 
modeling, the focus is only on cell/module/array. The simplest equivalent circuit of a solar cell is a current source in parallel with a diode Fig. 2.

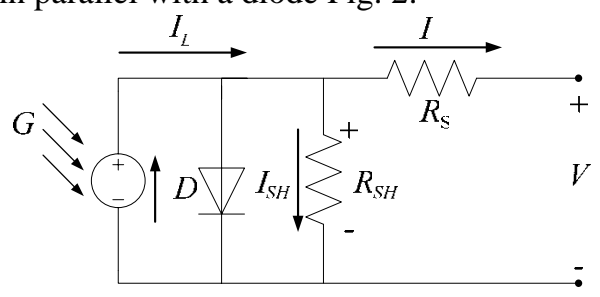

Fig. 2. Circuit diagram of the PV model

Increasing sophistication, accuracy and complexity can be introduced to the model by adding in turn [7]:

- Temperature dependence of the diode saturation current $I_{0}$.

- $\quad$ Temperature dependence of the photo current $I_{L}$.

- Series resistance $R_{s}$, which gives a more accurate shape between the maximum power point and the open circuit voltage. This represents the internal losses due to the current flow.

- Shunt resistance $R_{s h}$, in parallel with the diode, this corresponds to the leakage current to the ground and it is commonly neglected

- Either allowing the diode quality factor $n$ to become a variable parameter (instead of being fixed at either 1 or 2) or introducing two parallel diodes with independently set saturation currents.

In an ideal cell $R_{s}=R_{s h}=0$, which is a relatively common assumption [8]. For this paper, a model of moderate complexity was used. The net current of the cell is the difference of the photocurrent, $I_{L}$ and the normal diode current $I_{0}$ :

$$
I=I_{L}(T)-I_{0}\left(e^{\frac{q\left(V+I R_{S}\right)}{n k T}}-1\right)
$$

The model included temperature dependence of the photo-current $I_{L}$ and the saturation current of the diode $I_{0}$.

$$
\begin{gathered}
I_{L}(T)=I_{L}\left(T_{1}\right)+\alpha\left(T-T_{1}\right) \\
I_{L}\left(T_{1}\right)=I_{S C}\left(T_{1, n o m}\right) \frac{G}{G\left({ }_{n o m}\right)} \\
V_{O C}(T)=V_{O C}\left(T_{1}\right)+\beta\left(T-T_{1}\right) \\
I_{0}=I_{o}\left(T_{1}\right) \times\left(\frac{T}{T_{1}}\right)^{\frac{3}{n}} e^{\frac{q V_{q}\left(T_{1}\right)}{n k\left(\frac{1}{T}-\frac{1}{T_{1}}\right)}} \\
I_{0}\left(T_{1}\right)=\frac{I_{S C}\left(T_{1}\right)}{\left(e^{\frac{q V_{O C}\left(T_{1}\right)}{n k T_{1}}}-1\right)}
\end{gathered}
$$

A series resistance $R_{s}$ was included; witch represents the resistance inside each cell in the connection between cells.

$$
R_{S}=-\frac{d V}{d I_{V_{O C}}}-\frac{1}{X_{V}}
$$

$$
X_{V}=I_{0}\left(T_{1}\right) \frac{q}{n k T_{1}} e^{\frac{q V_{O C}\left(T_{1}\right)}{n k T_{1}}}-\frac{1}{X_{V}}
$$

The shunt resistance $R_{s h}$ is neglected. A single shunt diode was used with the diode quality factor set to achieve the best curve match. This model is a simplified version of the two diode model presented by Gow and Manning [9]. The circuit diagram for the solar cell is shown in Figure 2. The PV array consists of a set of $M_{p}$ parallel branches each with $M_{s}$ modules in series (Fig. 3).

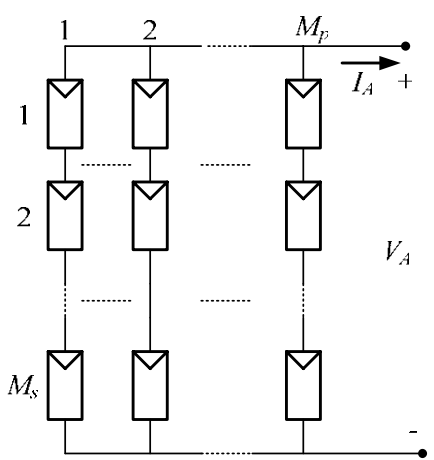

Fig. 3. General scheme of solar array

The applied voltage at the array's terminals is denoted by $V_{A}$, while total current of the array is se sum of individual module, if is assumed that the modules are identical and the ambient irradiation is the same on all modules, then the array current is:

$$
I_{A}=M_{p} I_{a}
$$

where $I_{a}$, is the current each module.

\section{1) PV Module Performance}

The model of the PV array was implemented, and typical parameter for a 300Watt module (Table I) was used to plot the $I$ - $V$ curves for various irradiation levels at $25^{\circ} \mathrm{C}$. The Fig. 4 show the maximum power point (MPP) and constant power curves for module simulated.

TABLE I. - Typical Electrical Characteristic of Module ${ }^{1}$

\begin{tabular}{|c|c|c|}
\hline Parameter & Variable & Value \\
\hline Maximum Power $\left(W_{p}\right)$ & $P_{m}$ & 300 \\
\hline Voltage@ $P_{m}(V)$ & $V_{m}$ & 51 \\
\hline Current @ $P_{m}(A)$ & $I_{m}$ & 5.90 \\
\hline $\begin{array}{c}\text { Open-circuit voltage }(V) \\
\text { Short circuit current }(A)\end{array}$ & $I_{S C}$ & 60 \\
\hline $\begin{array}{c}\text { Temperature coefficient of open-circuit } \\
\text { voltage }\left(\mathrm{mV} /{ }^{\circ} \mathrm{C}\right)\end{array}$ & $\beta$ & -228 \\
\hline $\begin{array}{c}\text { Temperature coefficient of short-circuit } \\
\text { current }\left(\mathrm{mA} /{ }^{\circ} \mathrm{C}\right)\end{array}$ & $\alpha$ & 6.50 \\
\hline $\begin{array}{c}\text { Temperature coefficient of Power } \\
\left(\% /{ }^{\circ} \mathrm{C}\right)\end{array}$ & & -0.47 \\
\hline Cells number & $n$ & 216 \\
\hline
\end{tabular}

NOTES:

1: The data are based on measurements made in a solar simulator at Standard Test Conditions (STC), which are: Illumination of $1 \mathrm{~kW} / \mathrm{m}^{2}$ (1 sun) at spectral distribution of AM 1.5; Cell temperature of $25^{\circ} \mathrm{C}$ or as otherwise specified (on curves) 


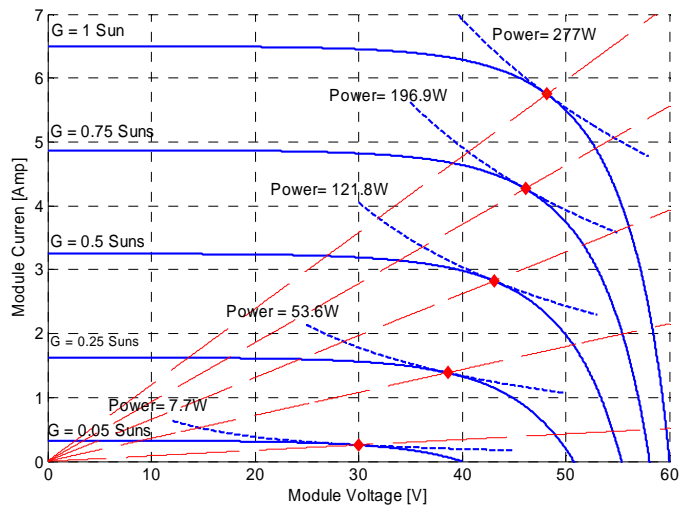

Fig. 4. I-V Curves for various irradiation levels

A typical a typical PV application of $130 \mathrm{~kW}_{\mathrm{p}} \mathrm{dc}$, using the PV module parameter of Table 1, can be sizing considering the inverter parameter data shown in the Table II.

TABLE II. - Typical Electrical Parameter for Inverter

\begin{tabular}{|c|c|}
\hline Parameter & Value \\
\hline Pac & $125.000 \mathrm{Watt}$ \\
\hline Pdc max & $130.000 \mathrm{Watt}$ \\
\hline Vdc max & $600 \mathrm{~V}$ \\
\hline$I d c$ max & $400 \mathrm{~A}$ \\
\hline Vmpt max & $600 \mathrm{~V}$ \\
\hline Vmpt min & $275 \mathrm{~V}$ \\
\hline Vmin & $250 \mathrm{~V}$ \\
\hline Power Factor & 1.0 \\
\hline Efficiency & $95.7 \%$ \\
\hline
\end{tabular}

The PV generator regulating, consist of a set of 64 parallel branches each with 7 modules in series. This array produces $101.21 \mathrm{kWp}$ at $289.1 \mathrm{~V}$, when the solar insolation (illumination) is $1000 \mathrm{Watt} / \mathrm{m}^{2}$, and the ambient temperature is $40^{\circ} \mathrm{C}$ (maximum).

\section{B. Inverter}

As known, the PV arrays produce DC power, and then a $\mathrm{DC} / \mathrm{AC}$ conversion is required. Important considerations must be done when PV system interacts with ac system.

\section{1) Requirements of the Control System}

The control inverters used to supply power to an ac system in a distributed environment should be based on information that is locally at the inverter [3] due large distance between inverters, may make the communication of information impractical. Though this communication can be used to enhance the performance, must be not critical for system operation. Then, the inverter control should be based on terminal quantities [3]. The control of the active and reactive power flow to the grid is performed by the inverter. The $P$ and $Q$ flows in ac system are coupled For small changes $P$ is predominantly dependent on the power angle, while Q is dependent on the magnitude of the converter's voltage [1].

$$
P=\frac{E V}{\omega L} \operatorname{sen} \delta
$$

$$
Q=\frac{V^{2}}{\omega L}-\frac{E V}{\omega L} \cos \delta
$$

These provide for a basic feedback loops for the control of output power and bus voltage, through regulation of reactive power flow. Considering only the fundamental frequency, the circuit equivalent and phasor diagram of the inverter is given in the Fig. 5.

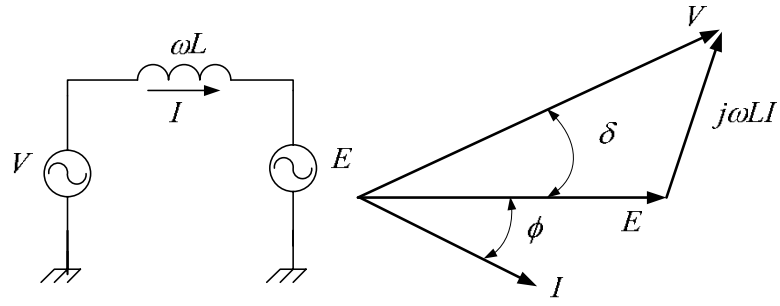

Fig. 5. Fundamental frequency equivalent circuit and phasor diagram for the output converter

The real and reactive power fed into the ac system are two variables that are controlled by the inverter [3]. Given two points for real and reactive power $P^{*}$ and $Q^{*}$, the real and reactive power, $P$ and $Q$ into ac system can be controlled by different ways. The determination of the $P^{*}$ and $Q^{*}$ reference values depends on the specific application and installation considered [4]. If the inverter is current controlled, then the full decoupling of the active and reactive power regulation loops can be easily achieved, employing the vector control principle. The entire control is performed in stationary $d-q$ reference, being the transformation from the physical $a-b-c$ frame to stationary $d-q$ reference frame described by:

$$
\begin{gathered}
f_{d}=\frac{2}{3}\left(-\frac{\sqrt{3}}{2} f_{b}+\frac{\sqrt{3}}{2} f_{c}\right) \\
f_{q}=\frac{2}{3}\left(f_{a}-\frac{1}{2} f_{b}-\frac{1}{2} f_{c}\right)
\end{gathered}
$$

The $f$ quantity denotes a physical quantity, such as voltage or current. In absence of a neutral connection, the cero quantity is of no interest [3]. Using the output voltage measure of the inverter in stationary $d-q$ reference and the $P^{*}$ and $Q^{*}$ reference values, can be derived the setpoint of current in stationary $d$ - $q$ reference frame:

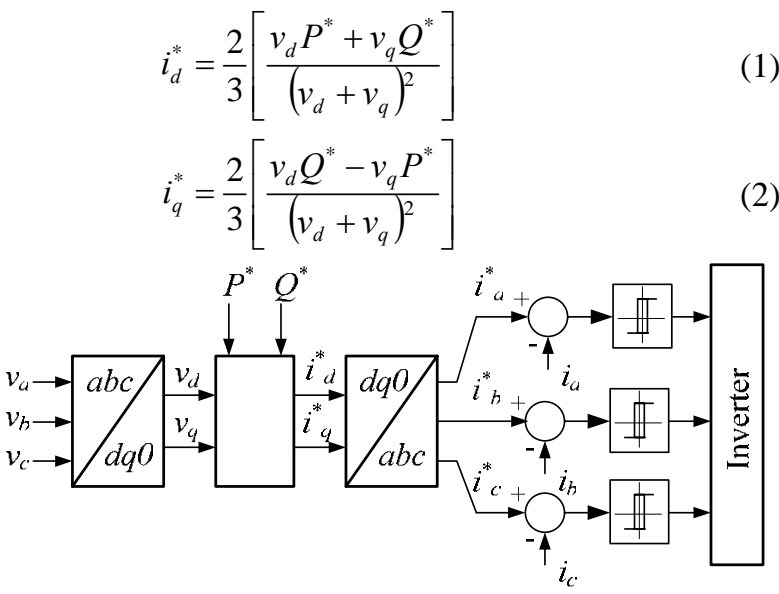

Fig. 6. Active and reactive power regulation with a current controlled inverter 
The reference current in $a-b$ - $c$ frame, are compared with measured output current, and the error of each phase current is controlled by a two level hysteresis comparator sensitizing the switching logic to the inverter.

\section{2) Stand-alone Performance}

The control scheme of Fig. 6 applied to the power system of Fig. 1, was simulated. For this simulation, the PV generator was simulated like constant DC voltage source considering constant conditions of insulation and temperature over PV module. Then, the dc bus voltage is taken constant to be 1 p.u, and the ac system is a $60 \mathrm{~Hz}$. sine waveform 1 p.u rms. The inductor filter is turned to be $17 \mathrm{mHy}$. Initially, the inverter fed to the ac system $P^{*}=$ 1 p.u, and $Q^{*}=0.5$ p.u., in steady state. Step changes on $Q^{*}$ and $P^{*}$ successively was simulates, and the result are shown in Fig. 7 and 8. The Fig. 7, show the inverter lineto-line voltage waveform, and the inverter controller, for $P^{*}=1$ p.u. and $Q^{*}=1$ p.u. The Fig. 8 , show the inverter time response to step changes in $P^{*}$ and $Q^{*}$, is evident the coupling between $P$ and $Q$; Fig 5, show that there is a disturbance in $P$ when $Q^{*}$ is changed, and a disturbance in $Q$ when $P^{*}$ is changed.
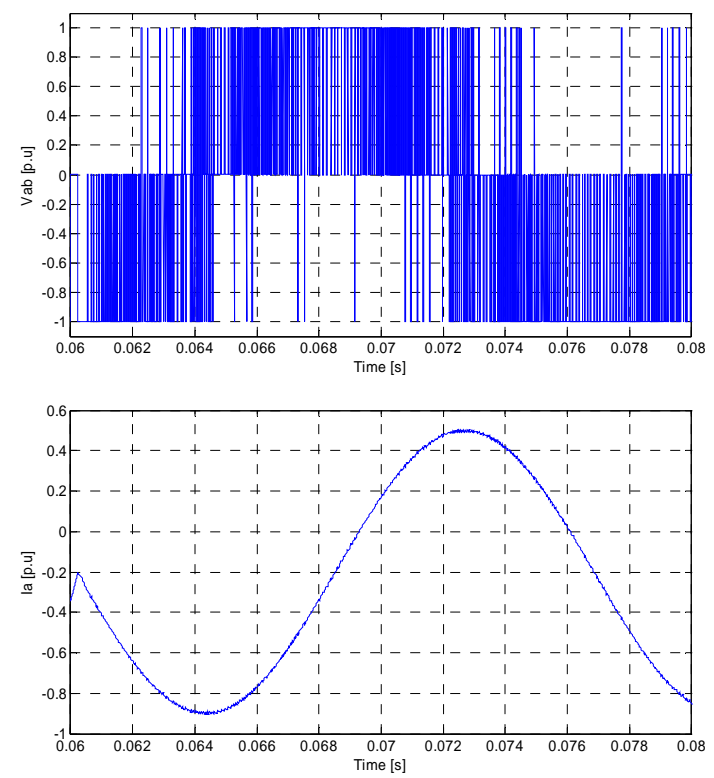

Fig. 7. Inverter voltage and current waveform
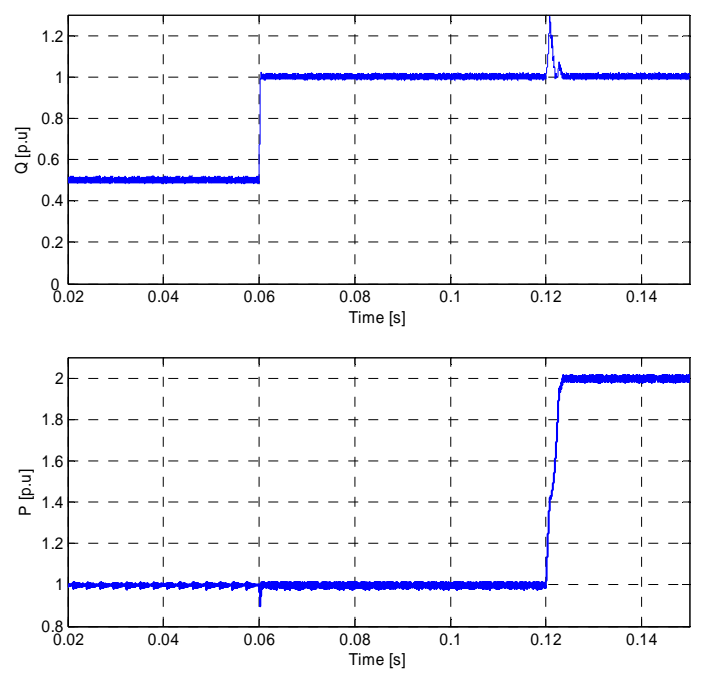

Fig. 8. Inverter real and reactive power output

\section{Simulation of Dynamic Behaviour}

Dynamic simulation of two PV plants (G2 and G11) operating to support of electrical grid are performed on the system in Fig. 9, witch is based on a distribution feeder in the Kumamoto area of Japan [11]. The network parameters are given in Appendix I, where the power base is 10 MVA and the base line voltage is $6.6 \mathrm{kV}$. G2 is connected to the bus 2, consist of a PV generator system, 3-phase, $P_{\text {rate }}=250 \mathrm{KW}, V_{\text {rate }}=6.6 \mathrm{kV}$. G11 is connected at bus 11, consist of a PV generator system, 3phase, $P_{\text {rate }}=1.5 \mathrm{MW}, V_{\text {rate }}=6.6 \mathrm{kV}$. The detailed parameters of both units are not due to space limits.

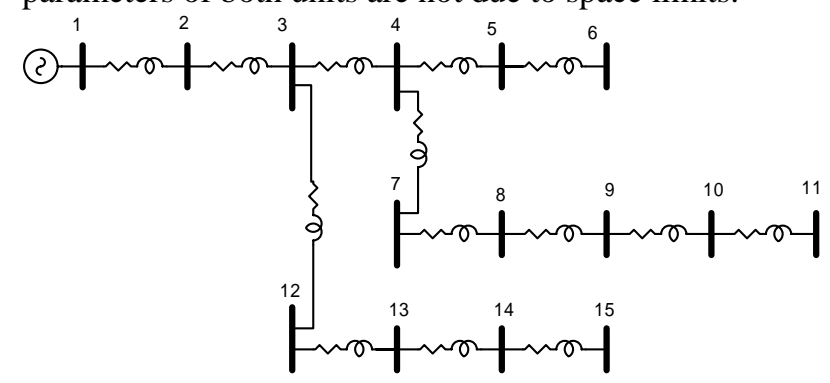

Fig. 9. 15 Bus Distribution System Diagram

A certain time, the total load of the distribution system is $P_{\text {load }}=6.301 \mathrm{MW}, Q_{\text {load }}=0.446 \mathrm{MVAR}$, and the solar insolation (illumination) is $958 \mathrm{Watt} / \mathrm{m}^{2}$, and the ambient temperature is $35^{\circ} \mathrm{C}$. The weather variables are assumed constant during dynamic simulation time. Assume there is a $5 \%$ of step increase in the total load at $t=0.05 \mathrm{~s}$, Fig 10 show the dynamic response of the tie-line flow, real power of G2, and real power of G11.

Fig 11 and 12 show the dynamic response of the tie-line flow, real power of $\mathrm{G} 2$, and real power of $\mathrm{G} 11$, to a $10 \%$ and $20 \%$ of step increase in the total load at $t=0.05 \mathrm{~s}$. From the simulations, observe the following:

- $\quad$ Originally, the PV plant G2 operates at 0.4p.u and G11 at 0.7 p.u. and the power delivered from the transmission system into the feeder as the tie line flow is 1 p.u.

- $\quad$ During the load fluctuations, the inverter follows the load changes. In fact, each PV system absorbs the local load chance in same percent.

- The time response of the each inverter is the same, and equivalent to 0.002s. The power response of the PV systems reaches a peak output in less than $0.001 \mathrm{~s}$. This peak up the major increases in the power load.

- The PV system is capable of providing effective grid-support, and exhibiting a good time response for step changes on power load.

\section{Conclusions}

In this paper a complete model for a PV system to provide grid-support is development. A PV generator is modeled with moderate complexity, including the temperature dependence and a complete set of parameter of the solar panel. An effective control scheme for VSI is presented. A important aspect of the control methodology developed here is that it is highly modular in nature, 
being suitable to DG applications. Evaluations of these models show that are reasonable and suitable for slow dynamic simulations. A distribution system with some PV system, demonstrated that feasibility the grid-support operation.

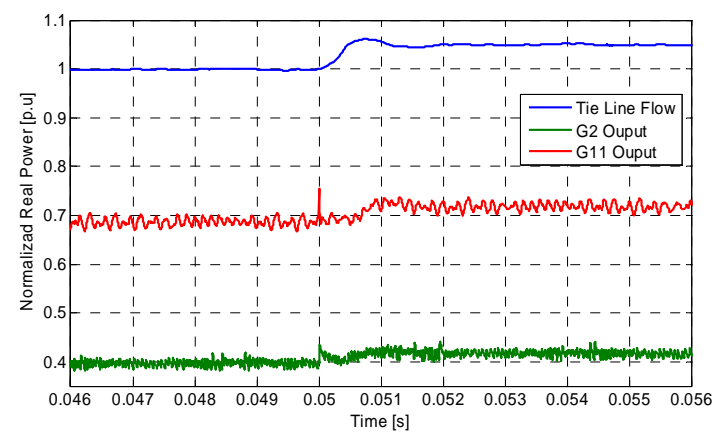

Fig. 10. Dynamic performance of PV system for 5\% step increases on total load

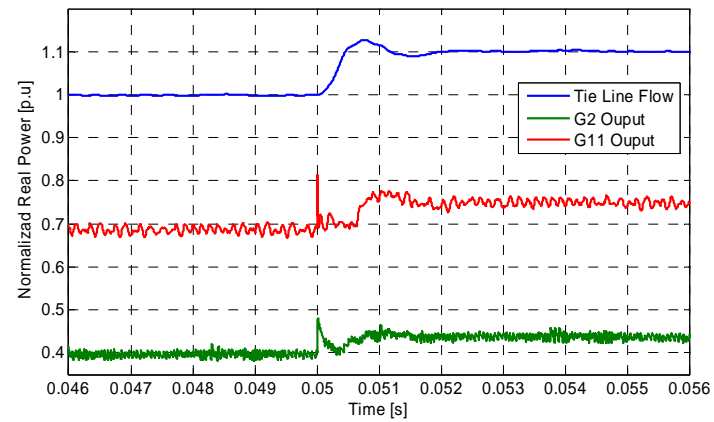

Fig. 11. Dynamic performance of PV system for $10 \%$ step increases on total load

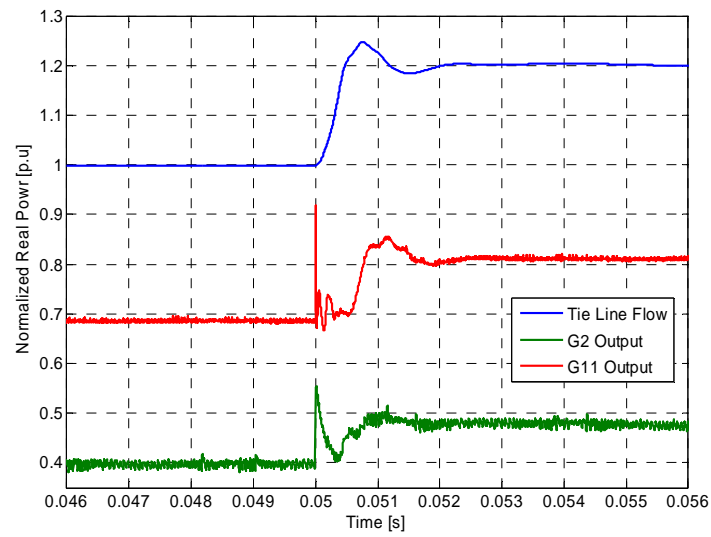

Fig. 12. Dynamic performance of PV system for $20 \%$ step increases on total load

\section{References}

[1] R. H. Lasseter. "Control of Distributed Resources”. Bulk Power System Dynamics and Control IV - Restructuring, August 24-28, Santorini, Greece.

[2] R. H. Lasseter, K. Tomsovic and P. Piagi. Scenarios for Distributed Technology Applications with Steady State and Dynamic Models of Loads and Micro-Sources . Consoritum for Electric Realiability Technology Solutions. http://eetd/lbl/gov/ea/CERTS/

[3] M.C. Chandorkar, D.M. Divan, and R. Adapa, "Control of parallel connected inverters in stand-alone ac supply systems," IEEE Trans. on Industry Applications, January/February 1993. pp. 136-143.
[4] L. Angquist and L. Lindbrg, "Inne phase angle control of voltragesource inverter in high power application”, IEEE PESC Conf. Rec. 1991. pp. 293-298.

[5] Lasseter R., Akhil A., et al. "Integration of Distributed Energy Resources: The CERTS MicroGrid Concept". http://eetd/lbl/gov/ea/CERTS/

[6] Kariniotakis G., Almeida R, Busquet S, et at. Large Scale Integration of Micro-Generation to Low Voltage Grids. TASK TA1: MICROSOURCE MODELLING, 2003

[7] G. Walker, "Evaluating MPPT converter topologies using a MATLAB PV model," Journal of Electrical \& Electronics Engineering, Australia, IEAust, vol.21, No. 1, 2001, pp.49-56.

[8] "Modeling New Forms of Generation and Storage", CIGRE TF38.01.10 November 2000.

[9] J. A. Gow, C. D. Manning "Development of a photovoltaic array model for use in power electronics simulation studies," IEE Proceedings on Electric Power Applications, vol. 146, no. 2, pp. 193-200, March 1999.

[10] S. Li, Tomsovic, and T. Hiyama, "Load Following functions using distributed energy resources", Proceedings of the IEEE PES Summer Meeting, Sattle. July 2000.

\section{Appendix I}

Line Data and Load Data Distribution Network

\begin{tabular}{|c|c|c|c|c|c|c|c|}
\hline $\begin{array}{c}\text { Brach } \\
\text { Number }\end{array}$ & $\begin{array}{c}\text { Sending } \\
\text { Node }\end{array}$ & $\begin{array}{c}\text { Ending } \\
\text { Node }\end{array}$ & $\begin{array}{c}\mathrm{R} \\
\text { (p.u) }\end{array}$ & $\begin{array}{c}\mathrm{X} \\
\text { (p.u) }\end{array}$ & $\begin{array}{c}\mathrm{B}^{1} \\
(\mathrm{p} . \mathrm{u})\end{array}$ & $\begin{array}{c}\mathrm{P}_{\mathrm{L}}{ }^{1} \\
\text { (p.u) }\end{array}$ & $\begin{array}{c}\mathrm{Q}_{\mathrm{L}}{ }^{1} \\
\text { (p.u) }\end{array}$ \\
\hline 1 & 1 & 2 & 0,0031 & 0,075 & 0 & 0,0208 & 0,0021 \\
\hline 2 & 2 & 3 & 0,0003 & 0,002 & 0,0015 & 0,0495 & 0,0051 \\
\hline 3 & 3 & 4 & 0,0067 & 0,031 & 0,0353 & 0,0958 & 0,0098 \\
\hline 4 & 4 & 5 & 0,0058 & 0,015 & 0,0025 & 0,0442 & 0,0045 \\
\hline 5 & 5 & 6 & 0,0141 & 0,037 & 0 & 0,0113 & 0,0012 \\
\hline 6 & 4 & 7 & 0,008 & 0,037 & 0,0312 & 0,0638 & 0,0066 \\
\hline 7 & 7 & 8 & 0,009 & 0,042 & 0 & 0,0323 & 0,0033 \\
\hline 8 & 8 & 9 & 0,007 & 0,032 & 0,0015 & 0,0213 & 0,0022 \\
\hline 9 & 9 & 10 & 0,0037 & 0,017 & 0,0035 & 0,028 & 0,0029 \\
\hline 10 & 10 & 11 & 0,009 & 0,042 & 0,002 & 0,217 & 0,0022 \\
\hline 11 & 3 & 12 & 0,0275 & 0,127 & 0 & 0,0132 & 0,0014 \\
\hline 12 & 12 & 13 & 0,0315 & 0,081 & 0 & 0,0029 & 0,0003 \\
\hline 13 & 13 & 14 & 0,0397 & 0,103 & 0 & 0,0161 & 0,0016 \\
\hline 14 & 14 & 15 & 0,0161 & 0,004 & 0 & 0,0139 & 0,0014 \\
\hline
\end{tabular}

: Receiving node.

Base Voltage $=6.6 \mathrm{kV}$, Base MVA $=10 \mathrm{MVA}$ 